\title{
EL ROSTRO HUMANO DE LAS PENSIONES ALIMENTARIAS: SU INFLUENCIA EN EL PROYECTO DE VIDA
}

\section{HUMAN FACE OF ALIMENTARY DEMANDS: ITS INFLUENCE IN THE LIFE PROJECT}

\author{
José Laurian Ramírez Díaz*
}

\section{RESUMEN}

Este artículo presenta los resultados de un estudio mixto de diseño correlacional explicativo, realizado con obligados alimentarios en Costa Rica, durante el primer semestre de 2018, el cual tuvo como objetivo, analizar la influencia de las demandas de pensión alimentaria sobre el proyecto de vida, logrando referir criterios de estos procesos y trascendiendo las descripciones meramente estadísticas sobre el fenómeno, con el fin de mejorar la comprensión de la vivencia que tienen estas personas en el afrontamiento de estas causas.

PALABRAS CLAVE: PENSIÓN * PADRE * JUSTICIA * AUTOESTIMA * CALIDAD DE VIDA

\section{ABSTRACT}

This article presents the results of a mixed study of corelational exploring design, did it with alimentary demand bound men from Costa Rica in first semester of 2018, which had the objective to analysis of the influence of alimentary demands in the life project, with the goal to describe the experience of the people who affront this kind of demands, trying to transcend the simple statistic description of this phenomenon.

KEYWORDS: PENSIONS * FATHERS * JUSTICE * SELF ESTEEM * QUALITY OF LIFE 


\section{INTRODUCCIÓN}

Por su cotidianeidad, existen fenómenos que se consideran "normales", entre ellos, las pensiones alimentarias. Por su frecuencia, puede caerse en una naturalización que derive en obviar la vivencia de las personas involucradas, situación que se pretende evitar en este artículo a partir de los hallazgos que se exponen en el estudio. Con base en ello, vale iniciar indicando que, según estadísticas del Poder Judicial, en Costa Rica se tramitaron 34 184 expedientes de pensión alimentaria en el 2013, la mayoría en la provincia de San José (Rojas, 2013). Para el año 2017, las solicitudes de órdenes de apremios por incumplimiento de pago fueron 33720 solo en las plataformas tecnológicas, según datos de la Dirección de Tecnología de Información del Poder Judicial (2017), por lo que se infiere que este fenómeno va en aumento.

Ante esto, algunos sectores consideran que existe un desbalance entre las partes involucradas; por un lado, están quienes defienden a la parte actora, alegando que los montos de manutención establecida por los juzgados son insuficientes con base en el costo de la vida, donde el promedio por familia es de $\$ 89000$ (ochenta y nueve mil colones), unos US $\$ 155$ (ciento cincuenta y cinco dólares estadounidenses) (Vásquez, 2017) y, por otro, están quienes consideran que el beneficio está circunscrito a ciertos abusos y más bien lesiona algunos derechos de la parte demandada por sujetarse, ocasionalmente, a la subjetividad del juzgador, donde se han dado casos en los que se fija una cuota desproporcionada, a veces con base en información falsa (Ruiz, 2017). Sobre esto, se ha descubierto que algunas personas han tenido que endeudarse para hacer frente a la obligación alimentaria (Ceciliano, Jiménez, Quesada, Rodríguez y Sandí, 2017). Hernández (2018) explica que "los derechos a la vida, salud, vivienda, educación y a un medioambiente sano y equilibrado son derechos inherentes a toda persona. Aunque parece innecesario decirlo, esto incluye a las personas alimentantes" (p.54), situación que, para los defensores de los derechos de los demandados, recurrentemente queda delegada a un segundo plano.
Si bien es cierto que la materia tratada es de naturaleza jurídica, no debe obviarse la integralidad del ser humano, a quien le afecta toda situación vivida en los distintos ámbitos y entornos, tales como: el social, familiar, conyugal, laboral, etc. De este modo, es importante considerar este fenómeno con base en aristas socioeducativas analizadas desde la configuración del proyecto de vida, tales como: el desarrollo humano, sus procesos y necesidades, el bienestar integral, el desarrollo vocacional, entre otros.

A pesar de que no existen estadísticas claras sobre la edad promedio de los deudores alimentarios, puede partirse de que la mayoría se encuentra en una etapa productiva que les facilita tener un trabajo $y$ atender esta obligación. En este estudio se partió de que los demandados por Pensión Alimentaria (PA) tienen 18 años o más, edad en la que se adquiere la condición legal de adultez y se ejercen los deberes $y$ derechos inherentes en Costa Rica. Al respecto, se pueden considerar algunas tareas o condiciones normativas del desarrollo humano a partir de esta edad, según Papalia y Martorell (2017):

$\diamond \quad$ Adultez emergente (18 a 25 o 29 años): consolidada por la industrialización social y la revolución tecnológica, es una etapa exploratoria de posibilidades y oportunidades para experimentar nuevas $y$ diferentes formas de vida, donde no se asumen todos los roles adultos.

$\diamond \quad$ Adultez temprana (25 o 29 a 40 años): se consolidan relaciones de pareja y de confianza, e inicia la vida laboral. Erikson (1959) citado por Papalia y Martorell (2017), sostuvo que el desarrollo psicosocial se establecía a partir de la capacidad de intimidad frente al aislamiento, cuyo propósito es establecer relaciones de compromiso profundo con otras personas o, caso contrario, aislarse, asociado a la virtud del cuidado propio y de otros.

$\diamond \quad$ Adultez media (40 a 65 años): esta etapa se caracteriza por cambios sociales, emocionales $y$ fisiológicos por el proceso de envejecimiento, puliéndose habilidades 
como la pericia, la capacidad del pensamiento integrativo y la creatividad. Alrededor de los 40 años se presenta la crisis de generatividad frente al estancamiento dado el interés en orientar $y$ ayudar a los jóvenes, generar como persona y construir legados (Erikson, 1959, citado en Papalia y Martorell, 2017).

Es importante aclarar que la adultez tardía o vejez inicia a los 65 años y se prolonga hasta el final del ciclo vital, pero fue considerada para este estudio porque la Ley nro. 7654 excluye de dicha obligación alimentaria a adultos dentro de este rango de edad. Otro aspecto considerado fueron los procesos del desarrollo que, según Pereira (2012), son el Autoconocimiento, Conocimiento del medio, Toma de decisiones, Identidad y Proyecto de Vida (PV), este último como criterio fundamental para el estudio y como criterio particular que articula a los demás. Al respecto, el PV puede considerarse como la búsqueda de la autorrealización (Ramírez, 2016), siendo esta multidimensional y de involucramiento de distintas áreas como la personal, familiar, interpersonal y otras.

Para González (2017), el PV está relacionado con la Identidad porque está constituido desde la construcción personal guiada por la variedad, la elección y la voluntad. Por su parte, D’Angelo (2000, citado en Betancourth y Cerón, 2017) plantea que el PV "es un modelo ideal sobre lo que el individuo espera o quiere ser $y$ hacer, que toma forma concreta en la disposición real y sus posibilidades internas y externas de lograrlo, definiendo su relación hacia el mundo y hacia sí mismo, su razón de ser como individuo en un contexto $y$ tipo de sociedad determinada" (p.25). Para Gómez y Royo (2014), el PV es una construcción autorreflexiva.

Un tercer eje fue el desarrollo vocacional, el cual Donald Super, citado por Ramírez (2015), describió en cinco etapas:

1. Etapa de Crecimiento (4-14 años)

2. Etapa de Exploración (15-24 años)

3. Etapa de Establecimiento (24-44 años)

4. Etapa de Sostenimiento (44-65 años)

5. Etapa de Declinación (65 años en adelante)
La etapa analizada fue la de Establecimiento, esto por la edad del grupo etario representativo de la muestra, de la cual Ramírez (2015) explica que entre los 24 a los 30 años se llevan a cabo ensayos ocupacionales con base en responsabilidades individuales, $y$ entre los 31 a los 44 años se establecen actitudes ocupacionales, la productividad y las relaciones interpersonales. Es importante considerar la Teoría de Trayectorias y Transiciones, planteada por Bourdieu y Passeron (1964) en Dávila y Ghiardo (2005), que propone una estructura de transiciones vitales históricas inevitables basadas en la cultura, la sociedad, el sexo y la edad, donde cada época histórica tiene un "libreto" propio y las trayectorias de plano social o de relaciones de poder entre grupos, concernientes a las posiciones estructurales (producto) y las disposiciones subjetivas que producen (producción).

El concepto central de esta teoría es el habitus: "principios de generación y estructuración de prácticas y representaciones... generador de la estrategia que permite a los individuos hacer frente a situaciones imprevistas $y$ en constante cambio" (Bourdieu, 1977, citado por Lizardo, 2004, p.378). Para Davey (2009), el habitus es un proceso biográfico individual y de capital existencial inacabable y presionado o alineado con el contexto, que construye a la identidad personal con base en el estatus social.

Para el caso de la adultez, una de las transiciones más relevantes se refiere a la inserción al mundo del trabajo (Granada, 2011; Gil, 2009; Mora y Oliveira, 2009), algo de suma relevancia para este estudio por la posible influencia que tiene las PA en la gestión de los recursos económicos, materiales y personales. Asimismo, es posible que el habitus también sea influido, en tanto involucra dimensiones como la identidad, las tareas del desarrollo y la autoestima, todas relacionadas al PV.

Sobre la autoestima, De Mézerville (2005) la define como la percepción de valor y confianza que una persona tiene de sí misma $y$ que la motiva a manejarse con propiedad, de forma autónoma y satisfactoria en la vida, la cual presenta 6 componentes, tres internos $y$ tres externos (cuadro 1). 
CUADRO 1

COMPONENTES DE LA AUTOESTIMA

\begin{tabular}{cc}
\hline INTERNOS & EXTERNOS \\
\hline Autoimagen & Autorrealización \\
Autovaloración & Autoafirmación \\
Autoconfianza & Autocontrol \\
\hline
\end{tabular}

Fuente: De Mézerville (2005).

El componente interno de la autoimagen se refiere a cómo una persona piensa que es percibida por los demás; la autovaloración se basa en la importancia que cada personas se da a sí misma y, la autoconfianza considera a la capacidad que la persona cree tener para lograr metas. Respecto a los componentes externos, la autorrealización se basa en las tareas, propósitos o metas alcanzados en la vida; la autoafirmación es la aceptación que cada quien tiene sobre cómo es, y el autocontrol es la habilidad de priorizar cosas en la vida (De Mézerville, 2005). Es viable considerar que donde ha mediado una demanda, existió un conflicto que motivó el involucramiento de las autoridades judiciales para resolverlo, y que toda situación involucra integralmente a las personas, de modo que la hipótesis considerada para el estudio fue que las demandas de PA influyen en el PV del obligado alimentario.

Con todo lo anterior, la pregunta de investigación fue: ¿cómo influye el proceso de demanda de PA en el PV de los obligados alimentarios? Si bien es cierto que la Ley nro. 7654 , publicada en el Diario La Gaceta (1997) y que legisla este tema en Costa Rica, no distingue entre hombres y mujeres, por sus estadísticas el fenómeno tiene dos rostros: de las mujeres como parte actora y de los hombres como obligados alimentarios. Por esta razón, se planteó como objetivo general: analizar la influencia de las demandas de PA en el PV de los demandados. Con esto, se pretendió dar voz a los obligados alimentarios sobre su vivencia en el proceso.

\section{METODOLOGÍA}

El estudio fue mixto de diseño explicativo secuencial (DEXPLIS). La primera etapa constó en un análisis cuantitativo mediante un cuestionario de 89 proposiciones relacionadas a elementos constituyentes del PV. La cuantificación se dio con base en una escala de Likert de cuatro criterios: Total desacuerdo, En desacuerdo, De acuerdo y Total acuerdo, aplicada mediante un cuestionario en línea a una muestra probabilística de 206 varones, cuyos criterios de selección fueron: 1) los participantes tuvieran al menos una demanda de PA con sentencia en firme y 2) que no vivieran con la(s) persona(s) alimentante(s). La segunda etapa fue cualitativa y se basó en una entrevista a profundidad colectiva con tres participantes: dos varones obligados alimentarios y la esposa de uno de ellos, que recabó información con base en las dimensiones derivadas del análisis cuantitativo para profundizar en los hallazgos estadísticos. Las características de la muestra y participantes en la entrevista se describen en la tabla 1 y el cuadro 2.

TABLA 1

MUESTRA CUANTITATIVA

\begin{tabular}{lcc}
\hline RESIDENCIA & FRECUENCIA & PORCENTAJE \\
\hline San José & 114 & 55,3 \\
Cartago & 29 & 14,1 \\
Heredia & 27 & 13,1 \\
Puntarenas & 15 & 7,3 \\
Guanacaste & 10 & 4,9 \\
Limón & 7 & 3,4 \\
Alajuela & 2 & 1,0 \\
Extranjero & 2 & 1,0 \\
\hline TOTAL & 206 & 100,0 \\
\hline
\end{tabular}

Fuente: $\quad$ Elaboración propia (2018). 
CUADRO 2

PERFIL DE LOS PARTICIPANTES DE LA ENTREVISTA A PROFUNDIDAD

\begin{tabular}{cccc}
\hline PARTICIPANTE & EDAD & OCUPACIÓN & AÑO DE PRIMERA DEMANDA \\
\hline P1 & 35 & Ingeniero en Sistemas & 2015 \\
P2 & 29 & Asistente técnica & 2015 \\
P3 $(*)$ & 29 & Servicio al cliente & - \\
\hline
\end{tabular}

(*) Esposa del Participante 2.

Fuente: Elaboración propia (2018).

De esta manera, el estudio planteó dos hipótesis, una nula $\left(H_{0}\right)$ y una alternativa $\left(H_{1}\right)$, las cuales fueron:

$H_{\mathrm{o}}=$ El Proyecto de Vida no es influido por los cambios socioeconómicos y de trabajo atribuidos a las demandas de PA.

$H_{1}=$ La influencia de las demandas de PA en el Proyecto de Vida está relacionada significativamente a los cambios que los obligados alimentarios atribuyen a estas en sus condiciones socioeconómicas y de trabajo.
Para lo anterior, se consideraron criterios sobre la condición económica y de oportunidades laborales, así como, la experiencia en los procesos y el trato en los juzgados, la calidad, las metas y los objetivos de vida, el ejercicio de roles socio paternos, entre otros. La información estadística fue analizada con SPSS y la información cualitativa con Atlas.ti 8.

\section{RESULTADOS}

Se presenta, primeramente, el índice de fiabilidad lograda en los datos de la encuesta.

TABLA 2

PRUEBA DE KMO Y BARTLETT

\begin{tabular}{llr}
\hline Medida Kaiser-Meyer-Olkin de adecuación de muestreo & & 0,848 \\
\hline & Aprox. Chi-cuadrado & 4881,090 \\
Prueba de esfericidad de Bartlett & gl & 1378 \\
& Sig. & 0,000 \\
\hline
\end{tabular}

Nota: Datos analizados con sPss (2018).

El KMO obtenido fue de $0,848(\mathrm{~m}>0,6)$ y la prueba de esfericidad de Bartlett dio una significancia de 0,0 que demostró que los resultados obtenidos no fueron fortuitos. La varianza total explicada fue de $66,14 \%$, lográndose un porcentaje adecuado de explicación del fenómeno estudiado ( $v>50 \%)$. En la comprobación de hipótesis de investigación se obtuvo un índice de correlación bilateral $y$ significancia bilateral de 0,01 y 0,0 respectivamente, de modo que la hipótesis nula fue rechazada, validando la alternativa. Con esto, las demandas de PA influyen en el PV por los cambios socioeconómicos y de trabajo que los demandados atribuyen a estas (ver tabla 3). 
TABLA 3

COMPROBACIÓN DE CORRELACIÓN ENTRE INDICADORES

\begin{tabular}{llcc}
\hline & & $\begin{array}{c}\text { INFLUENCIA DE LA } \\
\text { DEMANDA DE PA EN } \\
\text { EL PROYECTO DE } \\
\text { VIDA }\end{array}$ & $\begin{array}{c}\text { CAMBIO EN } \\
\text { CONDICIONES } \\
\text { SOCIOECONÓMICAS } \\
\text { Y DE TRABAJO }\end{array}$ \\
\hline & Correlación de Pearson & 1 &, $457^{* *}$ \\
INFLUENCIA DE LA & Sig. (bilateral) & &, 000 \\
DEMANDA DE PA EN EL & Suma de cuadrados y productos vectoriales & 514,026 & 392,416 \\
PROYECTO DE VIDA & Covarianza & 2,507 & 1,914 \\
& $\mathrm{~N}$ & 206 & 206 \\
\hline $\begin{array}{l}\text { CAMBIO EN } \\
\text { CONDICIONES }\end{array}$ & Correlación de Pearson &, $457^{* *}$ & 1 \\
SOCIOECONÓMICAS Y Y (bilateral) & Suma de cuadrados y productos vectoriales &, 000 & 1435,261 \\
DE TRABAJO & Covarianza & 392,416 & 7,001 \\
& $\mathrm{~N}$ & 1,914 & 206 \\
\hline
\end{tabular}

**La correlación es significativa en el nivel 0,01 (bilateral).

Nota: Datos analizados con sPss (2018).

INFLUENCIA DE LAS DEMANDAS DE PA EN EL PROYECTO DE VIDA

Con un Alfa de Cronbach de 0,929, la tabla 4 sintetiza los resultados del indicador.

Los ítems que compusieron el estudio se indican en la tabla 5.
La mayoría de la muestra indicó que las demandas por PA les han influido en su Proyecto de Vida, lo cual dio razón a la hipótesis de investigación. Más del 78\% y cerca del 19\% mostró estar Muy de acuerdo y De acuerdo con ello respectivamente, refiriendo criterios como limitaciones para el aprovechamiento

TABLA 4

INFLUENCIA DE LAS DEMANDAS DE PA EN EL PV

\begin{tabular}{lcc}
\hline & FRECUENCIA & PORCENTAJE \\
\hline Total Desacuerdo & 1 & 0,5 \\
En Desacuerdo & 4 & 1,9 \\
De Acuerdo & 39 & 18,9 \\
Total Acuerdo & 162 & 78,6 \\
\hline TOTAL & 206 & 100,0 \\
\hline
\end{tabular}

Nota: Datos analizados con SPSs (2018). 
TABLA 5

ÍTEMS DE LA INFLUENCIA DE DEMANDAS DE PA EN EL PV

\begin{tabular}{|c|c|c|c|c|c|}
\hline & $\begin{array}{l}\text { MEDIA DE } \\
\text { ESCALA } \\
\text { SI EL } \\
\text { ELEMENTO } \\
\text { SE HA } \\
\text { SUPRIMIDO }\end{array}$ & $\begin{array}{c}\text { VARIANZA } \\
\text { DE ESCALA } \\
\text { SI EL } \\
\text { ELEMENTO } \\
\text { SE HA } \\
\text { SUPRIMIDO } \\
\end{array}$ & $\begin{array}{l}\text { CORRELACIÓN } \\
\text { TOTAL DE } \\
\text { ELEMENTOS } \\
\text { CORREGIDA }\end{array}$ & $\begin{array}{l}\text { CORRELACIÓN } \\
\text { MÚLTIPLE AL } \\
\text { CUADRADO }\end{array}$ & $\begin{array}{c}\text { ALFA DE } \\
\text { CRONBACH } \\
\text { SI EL } \\
\text { ELEMENTO } \\
\text { SE HA } \\
\text { SUPRIMIDO }\end{array}$ \\
\hline $\begin{array}{l}\text { Creo que soy otra persona } \\
\text { después de la pensión } \\
\text { alimentaria }\end{array}$ & 60,51 & 69,889 & 0,700 & 0,569 & 0,923 \\
\hline $\begin{array}{l}\text { Mis planes de vida cambiaron } \\
\text { con la demanda de pensión } \\
\text { alimentaria }\end{array}$ & 60,36 & 70,830 & 0,747 & 0,657 & 0,922 \\
\hline $\begin{array}{l}\text { La pensión alimentaria me } \\
\text { ha limitado oportunidades en } \\
\text { la vida }\end{array}$ & 60,38 & 70,551 & 0,725 & 0,592 & 0,923 \\
\hline $\begin{array}{l}\text { Creo que mi familia se ha visto } \\
\text { afectada, de alguna forma, por } \\
\text { mi pensión alimentaria }\end{array}$ & 60,27 & 72,960 & 0,603 & 0,447 & 0,925 \\
\hline $\begin{array}{l}\text { He renunciado a sueños } \\
\text { que tenía por alguna causa } \\
\text { relacionada a la pensión } \\
\text { alimentaria }\end{array}$ & 60,50 & 70,289 & 0,661 & 0,484 & 0,924 \\
\hline $\begin{array}{l}\text { A veces siento frustración } \\
\text { debido a la pensión } \\
\text { alimentaria }\end{array}$ & 60,25 & 72,606 & 0,694 & 0,584 & 0,924 \\
\hline $\begin{array}{l}\text { He sentido desesperación } \\
\text { a causa de la pensión } \\
\text { alimentaria }\end{array}$ & 60,26 & 72,317 & 0,654 & 0,524 & 0,924 \\
\hline $\begin{array}{l}\text { He dejado metas de lado } \\
\text { a causa de la demanda de } \\
\text { pensión alimentaria }\end{array}$ & 60,43 & 71,151 & 0,663 & 0,501 & 0,924 \\
\hline $\begin{array}{l}\text { Mi salud física se ha visto } \\
\text { afectada con la demanda } \\
\text { alimentaria }\end{array}$ & 60,49 & 70,470 & 0,641 & 0,503 & 0,924 \\
\hline $\begin{array}{l}\text { La demanda de pensión } \\
\text { alimentaria cambió la forma } \\
\text { en cómo me veo a mí mismo/a }\end{array}$ & 60,61 & 70,220 & 0,596 & 0,459 & 0,926 \\
\hline $\begin{array}{l}\text { He sentido estrés debido a } \\
\text { la pensión alimentaria en el } \\
\text { último año }\end{array}$ & 60,22 & 73,803 & 0,507 & 0,367 & 0,927 \\
\hline
\end{tabular}




\begin{tabular}{|c|c|c|c|c|c|}
\hline & $\begin{array}{c}\text { MEDIA DE } \\
\text { ESCALA } \\
\text { SI EL } \\
\text { ELEMENTO } \\
\text { SE HA } \\
\text { SUPRIMIDO }\end{array}$ & $\begin{array}{c}\text { VARIANZA } \\
\text { DE ESCALA } \\
\text { SI EL } \\
\text { ELEMENTO } \\
\text { SE HA } \\
\text { SUPRIMIDO }\end{array}$ & $\begin{array}{c}\text { CORRELACIÓN } \\
\text { TOTAL DE } \\
\text { ELEMENTOS } \\
\text { CORREGIDA }\end{array}$ & $\begin{array}{l}\text { CORRELACIÓN } \\
\text { MÚLTIPLE AL } \\
\text { CUADRADO }\end{array}$ & $\begin{array}{c}\text { ALFA DE } \\
\text { CRONBACH } \\
\text { SI EL } \\
\text { ELEMENTO } \\
\text { SE HA } \\
\text { SUPRIMIDO }\end{array}$ \\
\hline $\begin{array}{l}\text { El monto que pago por } \\
\text { pensión alimentaria ha } \\
\text { dificultado algunos proyectos } \\
\text { que tenía }\end{array}$ & 60,33 & 72,202 & 0,640 & 0,550 & 0,925 \\
\hline $\begin{array}{l}\text { La pensión alimentaria } \\
\text { cambió mi estatus social }\end{array}$ & 60,60 & 69,804 & 0,650 & 0,500 & 0,924 \\
\hline $\begin{array}{l}\text { Siento que mis proyectos se } \\
\text { vinieron al suelo por causa de } \\
\text { la pensión alimentaria }\end{array}$ & 60,44 & 71,333 & 0,668 & 0,511 & 0,924 \\
\hline $\begin{array}{l}\text { Tengo limitaciones para } \\
\text { estudiar a causa de lo que } \\
\text { pago por pensión alimentaria }\end{array}$ & 60,47 & 70,298 & 0,612 & 0,482 & 0,925 \\
\hline $\begin{array}{l}\text { Tuve que dejar proyectos } \\
\text { personales de lado por la } \\
\text { pensión alimentaria }\end{array}$ & 60,33 & 72,593 & 0,628 & 0,459 & 0,925 \\
\hline $\begin{array}{l}\text { La demanda de pensión } \\
\text { alimentaria cambió mi forma } \\
\text { de relacionarme con otras } \\
\text { personas }\end{array}$ & 60,71 & 70,235 & 0,554 & 0,438 & 0,927 \\
\hline $\begin{array}{l}\text { Siento que algunas personas } \\
\text { me ven diferente a causa de la } \\
\text { pensión alimentaria }\end{array}$ & 60,86 & 70,294 & 0,505 & 0,316 & 0,929 \\
\hline
\end{tabular}

Nota: Datos analizados con SPSs (2018).

de oportunidades, afectación a la familia, sentimientos de frustración, afectación a la salud física y episodios de estrés, dificultades para materializar proyectos, cambios en el estatus social, limitaciones para estudiar y afectación en las relaciones interpersonales, todos considerandos como parte del PV (Hernández y Carranza, 2017; Vakil, 2018; De Mézerville, 2005).

Es muy probable que en una demanda por PA con sentencia haya existido un con- flicto que, por no conciliarse entre las partes oportunamente, dio pie a su resolución en ámbitos judiciales, lo cual influye en las condiciones de vida y que en Costa Rica, representa una situación cuantiosa: 33720 solicitudes de demanda interpuestas en 2016 solo en las plataformas tecnológicas (Dirección de Tecnología de Información del Poder Judicial, 2017). Para ampliar los criterios de análisis, la tabla 6 compara el ingreso mensual con el monto por PA. 


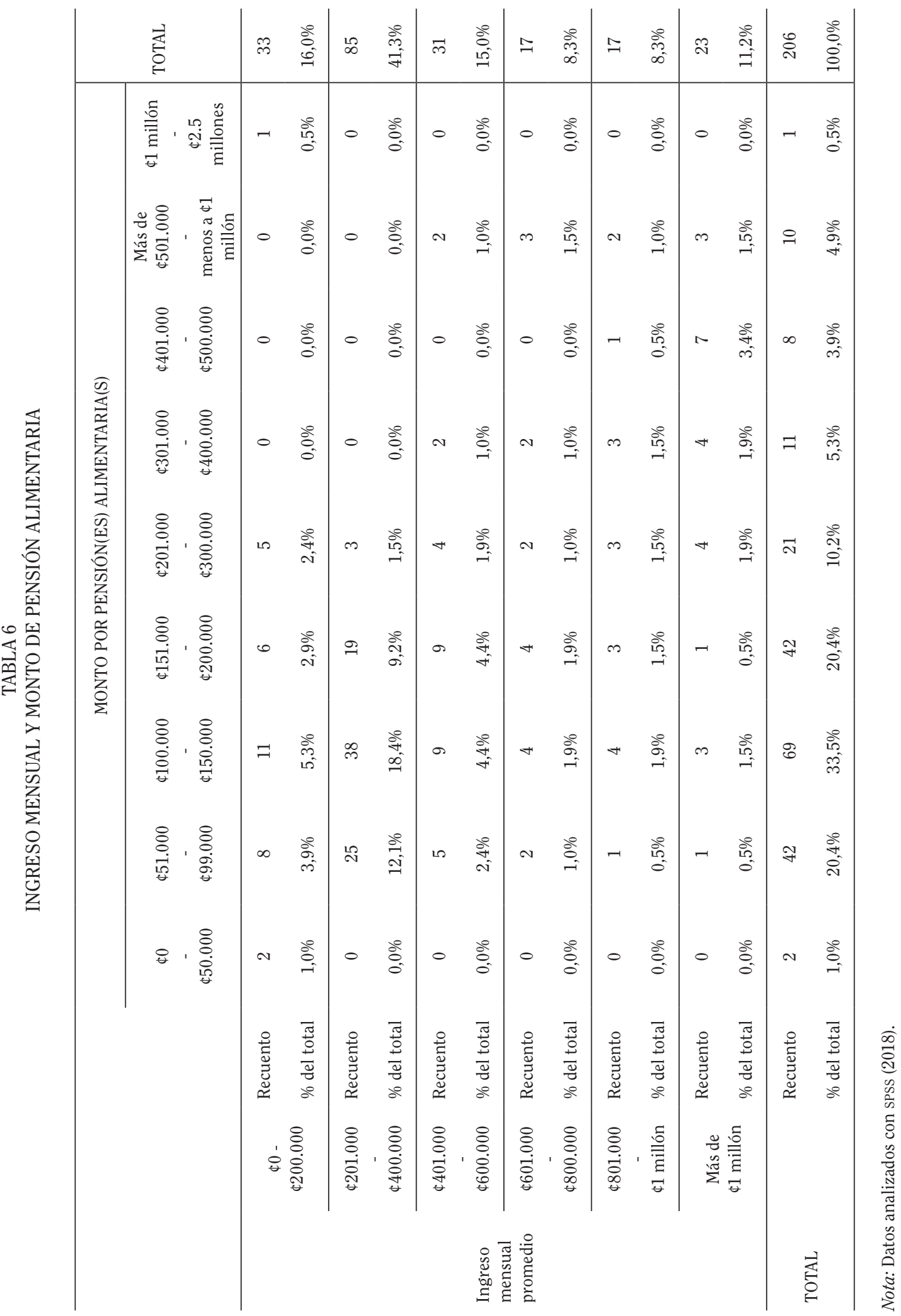


El $41,3 \%$ de la muestra percibía un ingreso mensual de entre $\$ 201000$ a $\$ 400000$ (us $\$ 350$ a us $\$ 700$ ), donde el $18,4 \%$ cancelaba montos de PA entre $\$ 100000$ a $\$ 150000$ al mes (us\$174 a us\$261), una cantidad mayor al promedio de \$89.000 (us\$155) (Vásquez, 2017). En general, la obligación alimentaria abarca el 41,6\% de los ingresos del demandado. Es importante considerar dos particularidades de la muestra del estudio: 1) 3 de cada 10 hombres tienen hijos ajenos a aquellos por quienes pagan PA; 2) el 66,5\% convive con alguna pareja, de modo que, una vez honrada la deuda alimentaria, la liquidez de sus ingresos mensuales tiene que repartirse entre las necesidades particulares y familiares. Sobre ello es importante rescatar que el PV considera distintas dimensiones, incluida a la familia $y$ la paternidad, la cual puede tener un valor sustantivo para muchos varones considerando que, aunque en los últimos años se ha aumentado la incursión afectiva de los padres en la crianza de la prole, prevalecen estereotipos entre ambos géneros que limitan al "buen padre" como "proveedor" (García, Hidalgo, López y Román, 2018), lo que podría limitar en la autorrealización al imponer una concepción materialista al rol masculino. Con base en esto, las siguientes frases dieron evidencia al respecto:

P3: Y vea que injusto también porque bueno, en el caso de él (refiriéndose a su esposo quien es obligado alimentario), él venía estudiando, verdá, siempre había estudiado, pasó todo esto de la pensión y la señora, verdá, que tiene a los hijos, ahora está estudiando, porque ella ya tiene una buena pensión, entonces ya él le alcanza para poder estudiar, y ya a él no le alcanza para seguir estudiando, o sea, que injusto es todo esto porque di, limita todo a uno el hombre. Se sabe que es responsabilidad, que bueno ahora que él y yo tenemos, eh, un hijo yo también la entiendo a ella porque yo soy mujer $y$ yo digo: un hijo sale caro, sale muy caro, pero es responsabilidad de las dos personas, o sea, ¿cómo es posible que vengan y pongan una pensión tan alta? y no digan: ah bueno sí, ¿un hijo gasta doscientos mil Colones por mes? Cien mil la mamá $y$ cien mil el papá.

P2: Pero entonces la vida de uno ya tiene que cambiar, entonces, ellos si tienen que ir a escuela privada pero mi hijo ya tiene que ir a una escuela pública, por ejemplo. Si ellos están acostumbrados a andar en microbús entonces, el que está en matrimonio tiene que estar, eh, caminando...

P1: ¿Por qué? Porque tengo una familia, sé lo que gastan, y sé lo limitado que estoy, entonces yo vivo con lo que, con lo que vive mi hija yo vivo.

Los obligados alimentarios perciben que la demanda de PA les afecta a ellos y a su familia, en especial a la prole, situación confirmada por P2 y P3. Esta afectación parece provocar el cambio de algunas condiciones para la persona y su contexto más cercano, lo cual deriva a variaciones en las condiciones de vida. Ante esto, Hernández (2018) recalca el derecho a una calidad de vida digna entre los obligados alimentarios, incluidas sus familias, situación que, como se verá a continuación, afecta a otras áreas del $\mathrm{PV}$, el cual es un ideal sobre lo que se quiere ser $y$ hacer (D’Angelo, 2000, citado en Betancourth y Cerón, 2017), por lo que la afectación a este, implica un replanteamiento de varias condiciones a futuro, tales como, las metas, algunas de las cuales tienen relación con condiciones económicas y laborales.

\section{INFLUENCIA DE LA PA A NIVEL ECONÓMICO Y LABORAL}

Con un Alfa de Cronbach de 0,814, esta dimensión se conformó por ítems sobre la influencia de la PA en la economía y el trabajo, a partir de limitaciones percibidas en las oportunidades laborales y la amenaza de despidos, así como, el rechazo a solicitudes de rebajo del monto de PA $y$ limitaciones en el acceso a créditos. La tabla 7 presenta el comportamiento del indicador y la tabla 8 los ítem que compusieron al mismo. 
TABLA 7

INFLUENCIA DE LAS DEMANDAS DE PA EN LA DIMENSIÓN ECONÓMICA Y EL TRABAJO

\begin{tabular}{lcc}
\hline & FRECUENCIA & PORCENTAJE \\
\hline Total Desacuerdo & 22 & 10,7 \\
En Desacuerdo & 53 & 25,7 \\
De Acuerdo & 62 & 30,1 \\
Total Acuerdo & 69 & 33,5 \\
\hline TOTAL & 206 & 100,0 \\
\hline
\end{tabular}

Nota: Datos analizados con SPSs (2018).

TABLA 8

ÍTEMS DE LA INFLUENCIA DE DEMANDAS DE PA EN LA CONDICIÓN SOCIOECONÓMICA Y DE TRABAJO

\begin{tabular}{|c|c|c|c|c|c|}
\hline & $\begin{array}{l}\text { MEDIA DE } \\
\text { ESCALA } \\
\text { SI EL } \\
\text { ELEMENTO } \\
\text { SE HA } \\
\text { SUPRIMIDO }\end{array}$ & $\begin{array}{c}\text { VARIANZA } \\
\text { DE ESCALA } \\
\text { SI EL } \\
\text { ELEMENTO } \\
\text { SE HA } \\
\text { SUPRIMIDO }\end{array}$ & $\begin{array}{c}\text { CORRELACIÓN } \\
\text { TOTAL DE } \\
\text { ELEMENTOS } \\
\text { CORREGIDA }\end{array}$ & $\begin{array}{l}\text { CORRELACIÓN } \\
\text { MÚLTIPLE AL } \\
\text { CUADRADO }\end{array}$ & $\begin{array}{c}\text { ALFA DE } \\
\text { CRONBACH } \\
\text { SI EL } \\
\text { ELEMENTO } \\
\text { SE HA } \\
\text { SUPRIMIDO }\end{array}$ \\
\hline $\begin{array}{l}\text { He sido rechazado/a en } \\
\text { concursos de plazas vacantes } \\
\text { por tener pensión alimentaria }\end{array}$ & 16,86 & 22,399 & 0,702 & 0,563 & 0,763 \\
\hline $\begin{array}{l}\text { He tenido que rechazar trabajos } \\
\text { por causas directas o indirectas } \\
\text { a la pensión alimentaria }\end{array}$ & 16,49 & 23,156 & 0,650 & 0,592 & 0,773 \\
\hline $\begin{array}{l}\text { Me han despedido del trabajo a } \\
\text { causa de la pensión alimentaria } \\
\text { alguna vez }\end{array}$ & 17,40 & 23,289 & 0,562 & 0,394 & 0,787 \\
\hline $\begin{array}{l}\text { He tenido que rechazar ofertas } \\
\text { de trabajo por alguna razón } \\
\text { debido a la pensión alimentaria }\end{array}$ & 16,52 & 22,765 & 0,629 & 0,577 & 0,775 \\
\hline $\begin{array}{l}\text { He solicitado rebaja del monto } \\
\text { de pensión alimentaria porque } \\
\text { considero que es alta }\end{array}$ & 16,47 & 24,546 & 0,463 & 0,230 & 0,804 \\
\hline $\begin{array}{l}\text { He tenido órdenes de apremio } \\
\text { por falta de pago de pensión } \\
\text { alimentaria en el último año }\end{array}$ & 16,97 & 23,166 & 0,461 & 0,231 & 0,809 \\
\hline $\begin{array}{l}\text { Me han rechazado créditos } \\
\text { bancarios por tener pensión } \\
\text { alimentaria }\end{array}$ & 16,53 & 25,022 & 0,430 & 0,273 & 0,809 \\
\hline
\end{tabular}

Nota: Datos analizados con SPSs (2018). 
Como se observó en la tabla 8 , el $63,6 \%$ de los obligados alimentarios indicaron estar De acuerdo o en Total acuerdo de que la PA tiene una influencia en su economía y trabajo, en una relación del 30,1\% y el 33,5\%. Esto parece devenir en ciertas restricciones percibidas que se plantean sobre la economía $y$ las oportunidades de trabajo, donde la carga al presupuesto mensual destinado a este pago, parece condicionar el acceso a créditos, lo cual se suma a la restricción migratoria que se impone en toda sentencia de PA per se, en el art. 14 de dicha ley, lo que podría limitar las oportunidades de trabajo $y$ de estudio que requieren que la persona salga del país. Un ejemplo sobre las limitaciones económicas por la PA se dio en el siguiente diálogo:

P3: Igual les afecta la pensión también para un crédito porque dicen: Ah bueno, gana tanto, pero pagan una pensión tanto...

P2: Si, para cualquier cosa...

P1: Eso es una, eso es de ya, o sea, usté dice: ¿Cuánto gano? Ta. Ta, ta, ta, pensión es como un cobro judicial, okey, usted ya no puede contar con esa plata, más eso...

P2: Sí, de los 400 mil más los 180 que le rebajan le quedan 220 , más la comida, más esto, Ah no no no, salga salga salga a este mae...

El acceso a los créditos es de suma valía para materializar proyectos como la compra de casa o financiamiento de estudios. Si el monto de la PA limita el acceso a estas oportunidades, el PV puede influenciar por limitaciones económicas y de oportunidades de trabajo, con posibles limitaciones para materializar objetivos personales $y$ beneficios familiares derivados, afectando, entre otras áreas, a la autoestima, la autonomía y el logro de metas (De Mézerville, 2005). La restricción migratoria de las demandas de Pa fue tratada en diálogos como el siguiente:
P2: Eso es lo que yo no entiendo, si usté tiene un trabajo estable la empresa es la encargada de pagar la pensión a esa persona, la empresa sabe que usté no se está yendo de inmigrante, está, va a ir a trabajar, y que va a volver, entoes, ¿cuál es problema? No entiendo yo eso. Nunca entendí eso

P1: Diay mae, muy simple...

P2: Hay que pagar como casi cuatro millones pa salir una semana

\section{P1: Exacto}

P2: Y le apuesto que uno paga esos 4 millones...

\section{P1: 14 meses}

P2: ...le apuesto que usté paga los 4 millones...

P1: Y le dicen que usté tiene plata...

P2: Y le dicen que usté tiene plata y le suben la pensión, se lo apuesto mae

P1: Y sube la pensión. O sea, esa es un, un arma de doble filo, entonces realmente, como le digo, o sea, uno está muerto en vida $y$ entonces le van cortando, le van cortando las alas, $y$ uno no se da cuenta

P2: Se limita, uno se limita mucho

Parece que existen limitaciones por la restricción migratoria impuesta en todas las demandas de PA, a lo que es importante indicar que, al respecto, Costa Rica es el país más rígido a nivel de la región ya que en promedio, un costarricense pasa 11 días en el extranjero, mientras que la garantía que la ley exige para salir del país son dos: o la solicitud del levantamiento de la restricción migratoria por la parte actora, o el depósito anticipado de 14 meses (las cuotas de todo un año, el aguinaldo y el bono de entrada a clases), es decir, 425 días (Nassar, 
2015). Esto parece afectar a los obligados alimentarios al prohibírseles salir del país y aprovechar oportunidades que así lo requieren, lo que parece generar frustración.

El estudio consideró la percepción que tienen los obligados alimentarios sobre el monto de Pa y cómo influye esto en su calidad de vida, lo cual derivó en una correlación entre ambos criterios hallada al momento de analizar la información. Es importante mencionar que los conceptos de justicia (respecto al monto fijado de PA) y calidad de vida son difíciles de precisar. Para este estudio se consideró, por un lado, la identificación de criterios de objetividad respecto al monto de PA $y$, por otro, la satisfacción de al menos las necesidades fisiológicas (alimento, vivienda, agua y otros) $y$ de seguridad (estabilidad $y$ orden) para los criterios de calidad de vida (Maslow, 1987, citado en Schultz y Schultz, 2010). El análisis correlacional obtuvo los resultados descritos en la tabla 9.

TABLA 9

CORRELACIÓN ENTRE MONTO DE PA Y LA PERCEPCIÓN DE CALIDAD DE VIDA

\begin{tabular}{|c|c|c|c|}
\hline & & $\begin{array}{l}\text { PERCEPCIÓN DE JUSTICIA } \\
\text { EN EL MONTO DE PA }\end{array}$ & $\begin{array}{l}\text { INFLUENCIA EN LA } \\
\text { CALIDAD DE VIDA }\end{array}$ \\
\hline \multirow{5}{*}{$\begin{array}{l}\text { Percepción de justicia } \\
\text { en el monto de PA }\end{array}$} & Correlación de Pearson & 1 &,$- 375^{* *}$ \\
\hline & Sig. (bilateral) & & 000 \\
\hline & $\begin{array}{l}\text { Suma de cuadrados y } \\
\text { productos vectoriales }\end{array}$ & 711,393 & $-246,620$ \\
\hline & Covarianza & 3,470 & $-1,203$ \\
\hline & $\mathrm{N}$ & 206 & 206 \\
\hline \multirow{5}{*}{$\begin{array}{l}\text { Influencia en la calidad } \\
\text { de vida }\end{array}$} & Correlación de Pearson &,$- 375^{* *}$ & 1 \\
\hline & Sig. (bilateral) & 000 & \\
\hline & $\begin{array}{l}\text { Suma de cuadrados y } \\
\text { productos vectoriales }\end{array}$ & $-246,620$ & 607,845 \\
\hline & Covarianza & $-1,203$ & 2,965 \\
\hline & $\mathrm{N}$ & 206 & 206 \\
\hline
\end{tabular}

** La correlación es significativa en el nivel 0,01 (bilateral). Nota: Datos analizados con sPss (2018).

Entre mayor sea la objetividad percibida en el monto de PA, es menor la idealización de su afectación a la calidad de vida, lo que deriva en una apreciación de justicia. Para entender mejor esto, se plantea el análisis de ambos elementos.
PERCEPCIÓN DE JUSTICIA EN EL MONTO DE PENSIÓN ALIMENTARIA

A continuación, se exponen los ítem que constituyeron este indicador (tabla 10). 
TABLA 10

ÍTEM DE LA PERCEPCIÓN DE JUSTICIA EN EL MONTO DE PENSIÓN ALIMENTARIA

\begin{tabular}{|c|c|c|c|c|c|}
\hline & $\begin{array}{l}\text { MEDIA DE } \\
\text { ESCALA } \\
\text { SI EL } \\
\text { ELEMENTO } \\
\text { SE HA } \\
\text { SUPRIMIDO }\end{array}$ & $\begin{array}{c}\text { VARIANZA } \\
\text { DE ESCALA } \\
\text { SI EL } \\
\text { ELEMENTO } \\
\text { SE HA } \\
\text { SUPRIMIDO }\end{array}$ & $\begin{array}{c}\text { CORRELACIÓN } \\
\text { TOTAL DE } \\
\text { ELEMENTOS } \\
\text { CORREGIDA }\end{array}$ & $\begin{array}{l}\text { CORRELACIÓN } \\
\text { MÚLTIPLE AL } \\
\text { CUADRADO }\end{array}$ & $\begin{array}{c}\text { ALFA DE } \\
\text { CRONBACH } \\
\text { SI EL } \\
\text { ELEMENTO } \\
\text { SE HA } \\
\text { SUPRIMIDO }\end{array}$ \\
\hline $\begin{array}{l}\text { El juez(a) fue objetivo con el } \\
\text { monto de pensión alimentaria }\end{array}$ & 7,84 & 7,723 & 0,564 & 0,339 & 0,714 \\
\hline $\begin{array}{l}\text { El juez(a) ha sido objetivo en } \\
\text { las audiencias que he tenido de } \\
\text { pensión alimentaria }\end{array}$ & 7,84 & 8,133 & 0,538 & 0,346 & 0,722 \\
\hline $\begin{array}{l}\text { El monto de mi pensión } \\
\text { alimentaria es justo con } \\
\text { respecto a mi salario }\end{array}$ & 7,86 & 7,961 & 0,569 & 0,378 & 0,714 \\
\hline $\begin{array}{l}\text { El monto de mi pensión } \\
\text { alimentaria provisional fue justo }\end{array}$ & 7,82 & 8,396 & 0,417 & 0,192 & 0,754 \\
\hline $\begin{array}{l}\text { Pago un monto de pensión } \\
\text { alimentaria justa para mi(s) } \\
\text { hijo(s) }\end{array}$ & 7,52 & 7,860 & 0,501 & 0,308 & 0,733 \\
\hline $\begin{array}{l}\text { La resolución de la demanda de } \\
\text { pensión alimentaria fue justa } \\
\text { para todas las partes }\end{array}$ & 8,04 & 8,789 & 0,467 & 0,235 & 0,741 \\
\hline
\end{tabular}

Nota: Datos analizados con SPSs (2018).

Es probable que la imposición inherente de las demandas de PA sea percibida de forma distinta entre las partes, en especial la percepción de justicia. Asimismo, es preciso considerar que esta concepción tiene distintas acepciones, de modo que la parte actora y la demandada pueden alegar sesgos. Sin embargo, para este indicador se consideraron criterios como la percepción de objetividad al fijarse el monto de pensión, la proporcionalidad entre este y el ingreso mensual, así como, el beneficio de la prole $y$ la percepción de justicia en general. Con un Alfa de Cronbach de 0,765, la tabla 11 sintetiza los resultados obtenidos. 
TABLA 11

PERCEPCIÓN DE JUSTICIA EN EL MONTO DE PENSIÓN ALIMENTARIA FIJADO

\begin{tabular}{lcc}
\hline & FRECUENCIA & PORCENTAJE \\
\hline Total Desacuerdo & 140 & 68,0 \\
En Desacuerdo & 53 & 25,7 \\
De Acuerdo & 10 & 4,9 \\
Total Acuerdo & 3 & 1,5 \\
\hline TOTAL & 206 & 100,0 \\
\hline
\end{tabular}

Nota: Datos analizados con SPSS (2018).

Como puede observarse, el $68 \%$ de encuestados mostró un Desacuerdo total de que el monto de pensión fuera justo, seguido del 25,7\% que estuvo en Desacuerdo. Estas situaciones son complejas de analizar por la subjetividad que suelen involucrar. Aun así, se puede decir que la percepción de justicia está relacionada a la cultura y la dinámica del entorno (García y Forero, 2014), al tratarse de construcciones colectivas que tienden a definir lo objetivo de lo que no lo es.

En ello prevalece la idea de que el hombre es el principal proveedor del núcleo familiar, por lo que es probable que esta situación presente alguna relación con las ideas referidas a las limitaciones que una PA puede tener para establecerse en un nueva relación de pareja, ampliar la prole $y$ materializar metas que requieren inversión económica, donde parece existir alguna prevalencia de ideas en las que el hombre tiene una responsabilidad destacada, por ser (o porque "debe ser") el principal proveedor.

A pesar de la complejidad de lo tratado, parece existir una idea de que es difícil conciliar o readecuar los montos de pa en los juzgados, una vez que este se fija, lo cual es contradictorio a la concepción proveedora del varón, ya analizado en el párrafo anterior, y que constituye un posible motivo de frustración traducido, posiblemente, en el Desacuerdo que se dio entre el $70 \%$ de los obligados alimentarios sobre la justicia en el monto de PA fijado. Algunos comentarios al respecto de esto fueron:
P3: Porque por más empieza a superar, más le siguen metiéndole más pensión y más pensión.

P1: ... nosotros estamos (...) muertos en vida. Nosotros no podemos tener nada, nosotros, nosotros no podemos progresar, porque si entre más ganamos más nos apretan, nosotros no podemos comprar nada porque nos lo pueden quitar, o sea, estamos.

P3: Dios guarde llegar yo y decir: No voy a trabajar, jamás, yo no puedo. Yo quiero dedicarme ahorita a estudiar $y$ no puedo, no puedo, porque él solo no va a poder con nosotros, jamás, no va a poder. Y él a veces, él me dice: Yo no sé qué haría yo solo...

P1: Imagínese que yo llegué a un estado, $y$ por esto tuve que tener tres trabajos y eso, que nuestra comida o nuestra, la cena o com, me la daba mi mamá, porque no nos alcanzaba pa, para pagar. El alquiler, en aquel tiempo pagábamos alquiler, la pensión, los abogados, y no teníamos, no nos alcanzaba.

Parece que la percepción generalizada es que el monto de la obligación alimentaria aumentará per se en caso de mejorar la condición económica, situación que se da en otros 
países y que no renuncia a las posibilidades de que en algunos casos haya sido así, de modo que la calidad de vida también será afectada. Con esto, el PV parece afectarse al verse limitadas oportunidades de la autorrealización, aunque es necesario aclarar que esto no se debe exclusivamente a la PA, sino a otras condiciones como el costo de vida, que afecta la calidad de vida de muchas personas.

\section{INFLUENCIA EN LA CALIDAD DE VIDA}

Esta dimensión presentó un Alfa de Cronbach de ,702 y se derivó de criterios como la necesidad de solicitar dinero prestado para honrar la obligación alimentaria, la afectación por el aumento en el monto de la PA y dificultades económicas relacionadas (ver tabla 12). Esta tabla presenta la síntesis del indicador según sus resultados.

TABLA 12

INFLUENCIA EN LA CALIDAD DE VIDA

\begin{tabular}{|c|c|c|c|c|c|}
\hline & $\begin{array}{c}\text { MEDIA DE } \\
\text { ESCALA } \\
\text { SI EL } \\
\text { ELEMENTO } \\
\text { SE HA } \\
\text { SUPRIMIDO }\end{array}$ & $\begin{array}{c}\text { VARIANZA DE } \\
\text { ESCALA SI EL } \\
\text { ELEMENTO } \\
\text { SE HA } \\
\text { SUPRIMIDO }\end{array}$ & $\begin{array}{c}\text { CORRELACIÓN } \\
\text { TOTAL DE } \\
\text { ELEMENTOS } \\
\text { CORREGIDA }\end{array}$ & $\begin{array}{l}\text { CORRELACIÓN } \\
\text { MÚLTIPLE AL } \\
\text { CUADRADO }\end{array}$ & $\begin{array}{c}\text { ALFA DE } \\
\text { CRONBACH } \\
\text { SI EL } \\
\text { ELEMENTO } \\
\text { SE HA } \\
\text { SUPRIMIDO }\end{array}$ \\
\hline $\begin{array}{l}\text { He tenido que pedir dinero } \\
\text { prestado para pagar la pensión } \\
\text { alimentaria }\end{array}$ & 7,57 & 0,989 & 0,545 & 0,298 & 0,636 \\
\hline $\begin{array}{l}\text { Mi calidad de vida se vería } \\
\text { afectada si pagara un monto } \\
\text { mayor de pensión alimentaria }\end{array}$ & 7,24 & 1,896 & 0,538 & 0,313 & 0,678 \\
\hline $\begin{array}{l}\text { Mi situación económica es } \\
\text { difícil debido a la pensión } \\
\text { alimentaria }\end{array}$ & 7,51 & 1,213 & 0,612 & 0,398 & 0,487 \\
\hline
\end{tabular}

Nota: Datos analizados con SPSs (2018).

TABLA 13

INFLUENCIA DE LA PA EN LA CALIDAD DE VIDA

\begin{tabular}{lcc}
\hline & FRECUENCIA & PORCENTAJE \\
\hline Total Desacuerdo & 4 & 1,9 \\
En Desacuerdo & 4 & 1,9 \\
De Acuerdo & 20 & 9,7 \\
Total Acuerdo & 178 & 86,4 \\
\hline TOTAL & 206 & 100,0 \\
\hline
\end{tabular}

Nota: Datos analizados con SPSs (2018). 
Con un porcentaje de $86,4 \%$, este indicador presentó uno de los acuerdos más notorios entre los participantes sobre la afectación de la pa en la calidad de vida. Aunque la consideración de los elementos de esta dimensión es compleja, como es el caso de la calidad de vida, un término que incorpora aportes de la medicina, la economía y las ciencias sociales (Urzúa y Caqueo-Urízar, 2012), para este caso se incluyó, como se mencionó, la satisfacción de al menos las necesidades fisiológicas.

Es importante destacar que según algunas perspectivas, las personas estructuran e integran su identidad a partir de su propia escala de valores, intereses, condiciones de su entorno y la afinidad por ciertas conductas, personas u objetos (Manuel, Sicilia, Lirola y Burgueño, 2016). Es importante considerar al habitus, el cual genera y estructura las prácticas y representaciones de afrontamiento a los cambios (Bourdieu, 1977 citado en Lizardo, 2004), que construye la identidad con base en el estatus social (Davey, 2009). Si las PA influyen en la calidad de vida de las personas, entonces influyen en el habitus, esto porque la insatisfacción de necesidades básicas parece producir niveles de frustración que podrían relacionarse a las limitaciones o dificultares para materializar metas referidas al PV, influidas por la obligación alimentaria. Esto puede verse reflejado en el siguiente diálogo:

P1: O sea, entonces uno, uno se siente como que ¿qué más puedo hacer yo? $\mathrm{O}$ sea, llega uno al punto que...

P2: Hacer las de Lester Morgan ¿Se acuerda quién era Lester Morgan? ${ }^{1}$

P1: Si, di, terminado el caso

Parece que la frustración produce idealizaciones de impotencia y restricciones en las

1 Lester Morgan fue un guardameta del Club Sport Herediano, quien se suicidó el 1 de noviembre de 2002 porque, según indicó en las cartas que dejó explicando las razones de su decisión, se sentía agobiado por las pensiones alimenticias que debía pagar por sus dos hijos. oportunidades para gestionar condiciones de balance entre la obligación alimentaria y la calidad de vida. Esto es importante de considerar ya que, aunado a la violencia vinculada al narcotráfico y la conducción temeraria, el suicido es una de las formas más recurrentes de interrupción de la vida entre varones costarricenses, donde figuran problemas pasionales y económicos entre las causas más frecuentes (Sección de Estadística del Departamento de Planificación del Poder Judicial, 2013; Cascante, 2016; Aguilar, 2017).

Sobre las limitaciones económicas, este es un elemento de consideración entre los obligados alimentarios, no solo porque representa una de las razones de endeudamiento (Ceciliano et ál, 2017), sino porque parece percibirse limitaciones en el acceso a la defensa pública para la parte demandada $y$, en muchos casos, es necesario buscar ayuda a nivel privado, cuyos costes profesionales son altos para cierto sector de la población. Esto se evidenció en el siguiente comentario:

P2: El toque igual con el abogado: a mí me recomendaron uno, y solo para que él pudiera ver el expediente me cobrara 450, solamente para poderlo ver, $y$ decirme a mí, este: —Tenés esto, hay que hacer esto, hay que hacer eso, sin decirme solamente el monto de cuánto me iba a cobrar. Cuando me dijo 450 mil yo le dije: -Di, gracias, no me alcanza, el salario no me da. (...) Okey, tal vez me hubiera bajado un toque la pensión, aunque no tenía plata para, porque estaba demasiada alta, porque para lo que yo gano, bueno. Diay, aquí estoy esperando todavía que me hagan el reajuste.

Otro aspecto considerado es la salud, la cual no trata solo de la ausencia de enfermedad, sino que involucra la integridad física, mental y social (Organización Mundial de la Salud, 2018). Sobre esta se dio el siguiente diálogo:

Entrevistador: ¿La salud de ustedes se ha visto afectada? 
P2: ¡Já!

P1: Ah, por supuesto

P2: Le voy a ser muy sincero: la mía, mentalmente, con lo que ha pasado, yo siento, más con el apellido del chiquito que me tiene, bueno, no re, cometí un error y el juzgado lo sabe, en el juzgado tienen que es un error, y aun así está igual (...)

P1: Agresión psicológicamente...

La integridad del ser humano implica una afectación multidimensional, sea por eventos estresantes, ansiedad o, incluso alegrías. En el caso de los obligados alimentarios entrevistados, la afectación de la PA en su calidad de vida es percibida en áreas que trascienden a la económica y distinguen otras como la psicológica, que se suma a las presuntas limitaciones en su PV para el establecimiento de relaciones de pareja, las posibilidades de aumentar su patrimonio e incluso, el ejercicio de su paternidad, lo cual puede relacionarse al conflicto que, generalmente, da pie a las demandas de la materia aquí tratada.

De este modo, las oportunidades que tienen la parte actora y la demandada sobre el acceso a la defensa judicial parece ser otro elemento que influye en la percepción del trato diferenciado a los obligados alimentarios, lo cual podría influir en el PV.

\section{OBJETIVOS DE VIDA}

Con un alfa de Cronbach de 0,754 e ítems referidos a la definición y claridad de los objetivos de vida, elementos clave para el PV (tabla 14).

TABLA 14

DEFINICIÓN Y CLARIDAD EN OBJETIVOS DE VIDA

\begin{tabular}{lcc}
\hline & FRECUENCIA & PORCENTAJE \\
\hline Total Desacuerdo & 32 & 15,5 \\
En Desacuerdo & 49 & 23,8 \\
De Acuerdo & 31 & 15,0 \\
Total Acuerdo & 94 & 45,6 \\
\hline TOTAL & 206 & 100,0 \\
\hline
\end{tabular}

Nota: Datos analizados con sPss (2018).

Los ítems que se consideraron en este indicador se mencionan en la tabla 15. 
TABLA 15

OBJETIVOS DE VIDA

\begin{tabular}{lcccc}
\hline & $\begin{array}{c}\text { MEDIA DE } \\
\text { ESCALA SI EL } \\
\text { ELEMENTO SE } \\
\text { HA SUPRIMIDO }\end{array}$ & $\begin{array}{c}\text { VARIANZA DE } \\
\text { ESCALA SI EL } \\
\text { ELEMENTO SE } \\
\text { HA SUPRIMIDO }\end{array}$ & $\begin{array}{c}\text { CORRELACIÓN } \\
\text { TOTAL DE } \\
\text { ELEMENTOS } \\
\text { CORREGIDA }\end{array}$ & $\begin{array}{c}\text { CORRELACIÓN } \\
\text { CUADRAD AL }\end{array}$ \\
\hline $\begin{array}{l}\text { Mis objetivos en la vida están } \\
\text { claramente definidos }\end{array}$ & 3,02 & 1,166 & 0,606 & 0,368 \\
\hline $\begin{array}{l}\text { Tengo claridad en las } \\
\text { prioridades en mi vida }\end{array}$ & 2,83 & 1,352 & 0,606 & 0,368 \\
\hline
\end{tabular}

Nota: Datos analizados con SPSs (2018).

Aunque cerca del 45,6\% de la muestra indicó tener claridad en la definición de sus objetivos, el segundo porcentaje en relevancia parece estar en desacuerdo con ello (23,8\%). Esto podría indicar que este criterio está dividido porque existen situaciones que trascienden a la demanda de PA y que refieren a una situación más compleja que involucra circunstancias como el replanteamiento de las metas, la adaptación de la relación con la prole y el cambio de condiciones referidas al monto de pensión, entre otras. Lo anterior pudo evidenciarse en comentarios como los siguientes:

P3: Y lo peor, que digámole un hombre con pensión, si empieza a superarse ya no puede tener nada a nombre de ellos.

P1: Si el mismo juzgado me metió una sentencia donde el juez dice que no tuve que asumir otras responsabilidades si no pude asumir la primera, o sea...

P3: $\ldots y$ no quiere decir que en un futuro ellos (los demandados alimentarios) ya no tengan derecho de volver a hacer su vida, como en el caso de él, que está joven $y$ todo $y$ en su momento tuvo sus dos hijos con la señora, este, bueno ella le metió uno tercero, no funcionó la relación y ¿por qué él no tiene derecho de ahora él hacer la vida conmigo $y$ tener los hijos que tal vez queramos tener?
Si bien, la ley no dificulta en sí las condiciones para que los obligados alimentarios reconstruyan la vida, sea con una nueva relación de pareja o nuevas paternidades, parece percibirse una limitación en la materialización de los objetivos de vida relacionada a las demandas de PA, especialmente por la capacidad económica que, en relación al monto de pensión, parece limitar el logro de ciertos proyectos. En este sentido, es importante mencionar que una de las facultades $y$ tareas normativas de la adultez es la capacidad de responzabilizarse por las decisiones $y$ actos mediante el afrontamiento de sus consecuencias (Papalia y Martorell, 2017), sin embargo, es probable que las condiciones expuestas en las frases anteriores refieran algunas limitaciones en la autonomía y la libertad para la acumulación y disfrute del patrimonio material y económico, lo cual podría referirse a la aparente amenaza percibida de que con esto incremente el monto de la pensión, así como, otras limitaciones para establecer nuevas relaciones de pareja por limitaciones financieras. Esto podría ser otra causa de frustración con implicaciones en la autoestima y, por tanto, influyente en el PV (Ramírez, 2015).

\section{INFLUENCIA DE LA PA EN ROLES DE VIDA}

Con un de Alfa de Cronbach de ,766 y constituida por ítems referidos a sentimientos de frustración por la afectación en el rol paterno, el indicador resultante se presenta en la tabla 16. 
TABLA 16

INFLUENCIA DE LA PAEN ROLES DE VIDA

\begin{tabular}{lcc}
\hline & FRECUENCIA & PORCENTAJE \\
\hline Total Desacuerdo & 17 & 8,3 \\
En Desacuerdo & 23 & 11,2 \\
De Acuerdo & 19 & 9,2 \\
Total Acuerdo & 147 & 71,4 \\
\hline TOTAL & 206 & 100,0 \\
\hline
\end{tabular}

Nota: Datos analizados con sPss (2018).

Al respecto de los ítems que configuraron esta dimensión, los datos se presentan en la tabla 17.

TABLA 17

INFLUENCIA DE LA PA EN ROLES DE VIDA

\begin{tabular}{lcccc}
\hline & $\begin{array}{c}\text { MEDIA DE } \\
\text { ESCALA SI EL } \\
\text { ELEMENTO SE } \\
\text { HA SUPRIMIDO }\end{array}$ & $\begin{array}{c}\text { VARIANZA DE } \\
\text { ESCALA SI EL } \\
\text { ELEMENTO SE } \\
\text { HA SUPRIMIDO }\end{array}$ & $\begin{array}{c}\text { CORRELACIÓN } \\
\text { TOTAL DE } \\
\text { ELEMENTOS } \\
\text { CORREGIDA }\end{array}$ & $\begin{array}{c}\text { CORRELACIÓN } \\
\text { CULALRE AL }\end{array}$ \\
\hline $\begin{array}{l}\text { El proceso de demanda de } \\
\text { pensión alimentaria fue } \\
\text { frustrante para mí }\end{array}$ & 3,32 & 1,113 & 0,622 & 0,387 \\
\hline $\begin{array}{l}\text { Mi rol paterno se vio afectado } \\
\text { por la demanda de pensión } \\
\text { alimentaria }\end{array}$ & 3,52 & 0,965 & 0,622 & 0,387 \\
\hline
\end{tabular}

Nota: Datos analizados con SPSS (2018).

La frustración fue un elemento recurrente, de modo que parece ser una consideración importante dentro de las demandas de Pa y que en este caso en particular, se relaciona con la paternidad. Como se mencionó, las demandas por pensión derivan de un posible conflicto inicial, de modo que influye en las dimensiones que constituyen al PV a partir de este supuesto, a lo que hay que sumarle, según la información obtenida, el ejercicio paterno, según los siguientes comentarios:

P1: Vea, eso es como, como leerse un libro de, de Heidy, mae sí, solo cuento, ¿por qué? Porque a la hora de llegada usté llega y dice: el código de niñez y adolescencia dice que está el papá o está la mamá, sino sigue el otro, mae, está clarísimo, mae, iclarísimo! o sea, no hay que ser muy matemático ni, mae, ni filólogo para entender eso, ¿se cumple? No no nada, para mí no, punto/Nosotros como hombres, como derecho procesal estamos mal, estamos desprotegidos.

Otra posible causal de frustración es la aparente etiqueta impuesta al hombre como un ser agresivo, según el siguiente diálogo: 
P1: Es una situación muy crítica porque en una separación lógicamente es porque hay conflictos, al final de cuentas uno es el agresivo, no sé...

\section{P2: Siempre es el hombre...}

Otro aspecto de aparente inconformidad $y$, por tanto, relacionado con sentimientos de frustración es el trato que perciben algunos varones al atrasarse en el pago de PA y la consecuente intervención policial para el apremio corporal:

P1: Diay a mí me hicieron un operativo, bueno yo trabajo ahí en oficinas centrales de la $\mathrm{Caja}^{2}$, y yo digo: mae, esos maes, la policía es algo espectacular mae, son super inteligentísimos, me van a esperar fuera del trabajo, llegan nueve policías $y$ dos cajones para detenerme. 0 sea, mae, eso parecía cuando hacen... (...) ¡Ni a un narco! Es algo inteligentísimos. Ah bueno, y llegan con aquel, aquella macho men, verdá, esperando a que uno se ponga agresivo o ponga resistencia 0 lo que sea para ver $y$ darle sopa de muñeca y uno dice, o sea, no, mae.

La aparente invisibilización o trato desigual que recibe el hombre en algunas oficinas públicas con funciones vinculadas al ejercicio de su paternidad, definida como el involucramiento afectivo del padre en la relación con su prole, así como, la participación responsable y afectiva de todas las actividades que realizan (Rivera et ál., 2004, citado en Blanco, Martínez $y$ Villate, 2014) fue otro tema conversado:

P2: [La madre de la menor] tiene demandas en el Patronato ${ }^{3}$, demandas en la escuela, ya tuvieron que llamar a mi mamá para que llegara por la chiquita porque el patronato se las iba a quitar.

2 Seudónimo de la Caja Costarricense del Seguro Social.
P3: Y no lo llaman a él.

Otra limitante de la paternidad es el aparente alejamiento que se da entre el obligado alimentario y su prole, así como, las consecuencias que esto deriva para ambas partes:

P3: Y el niño no, diay, pierden el cariño porque ellos son niños $y$ van perdiendo todo eso, o bien viene la mujer, digamos, no es el caso tal vez de ustedes dos, pero sí sé que tal vez el caso de muchos otros hombres, viene la mujer, se casa con otro hombre y el chiquito empieza a ver al otro hombre como papá, porque piensa que el papá fue un mal papá, pero en realidad no es así.

La presunción de que el sistema de justicia no trata por igual a hombres y mujeres fue otro de los temas tratados, según demuestra el siguiente diálogo:

P1: Uno se siente impotente, eso es lo primero, porque usted llega a un punto donde, eh, yo llevo sie, desde el 2011 peleando a mi hija, con la mamá...

P2: Sí, pero si peleás la pensión ella se la dan en menos de un mes

P1: Exacto. Y después de todo. Vea, yo he hecho, vea es tanto la la la, como dicen: eso es como, como dicen, burro amarrado contra león suelto, verdá, porque uno dice, o sea, yo llevo siete años peleando a mi hija, el abandono de la mamá, se la dan a la abuela, mae, la abuela fue un pleito...

Parece que la frustración percibida por los participantes presenta diferentes razones $y$ consecuencias. El ejercicio paterno está considerado como una tarea del desarrollo, dentro de la cual es importante destacar que, tanto en la encuesta como en la entrevista a profundidad, participaron adultos tempranos, entre los 25 a los 40 años, una etapa caracterizada por el establecimiento de relaciones de compromiso 
profundo o el aislamiento como contrapartes (Papalia y Martorell, 2017).

El alejamiento de la prole, sea por causas directas o indirectas al padre o por las limitaciones que en apariencia tienen los obligados alimentarios respecto a sus metas y la calidad de vida de ellos y sus hijos o hijas, parecen apuntar a que existe una influencia tangible de las demandas de PA en el PV, también manifestada en este ámbito, así como a la autoestima y a las emociones, de modo que la frustración es uno de los elementos más comunes dentro de estos procesos judiciales, por un aparente trato diferenciado hacia el varón por parte de algunos juzgados $y$ ciertas instituciones incidentes en las políticas de personas menores de edad.

Vale insistir en que las decisiones judiciales, al ser de acatamiento obligatorio, tienen un impacto en las partes implicadas $y$, en el caso de las sentencias de PA, su incumplimiento deriva en el apremio corporal. No puede descartarse que parte de la influencia que tienen estas demandas en el PV presentan, en cierta medida, criterios de falibilidad, al tratarse de decisiones tomadas por personas con envestidura jurídica, con rasgos característicamente intersubjetivos como tales (Colín y Monterrubio, 2010). En palabras de Manzanos (2004): "las decisiones tomadas por los jueces se ven potencialmente afectadas por sus factores intrínsecos, lo que torna dicha resolución parcialmente subjetiva" (p.181). Esta situación debe considerarse en los distintos estratos $y$ procesos de los juzgados de familia, ya que en todas las sentencias, incluidas las de PA, están involucrados seres humanos, ya sea como parte actora o demandada, que ven influidos sus PV y las dimensiones que constituyen su integralidad en este tipo de procesos.

\section{CONCLUSIONES}

La intervención de instancias judiciales en los procesos de PA parece iniciar por conflictos que no logran conciliarse satisfactoriamente, salvo por la intervención de una persona con investidura judicial, quien emite resoluciones de acatamiento para las partes, estableciendo criterios como el monto a cancelar con base en un análisis de las posibilidades de la parte demandada, así como, las necesidades de las personas beneficiarias. Esto, además del apremio corporal para las personas que no cumplen con su obligación alimentaria, son elementos que influyen en el Pv de las personas de distintas formas, el cual se establece como un proceso del desarrollo humano que articula a los demás (autoconocimiento, toma de decisiones, conocimiento del medio e identidad). De este modo, las demandas por PA influyen sustancialmente en el PV ya que involucran, integralmente, distintas dimensiones tanto intrínsecas (autoestima, metas y emociones) como extrínsecas (la capacidad de restablecerse en nuevas relaciones de pareja o la relación parental).

Las demandas de PA influyen en el PV desde las limitaciones percibidas en las oportunidades de estudio, acceso a créditos, mejora en las condiciones de vida en general $y$ en el trabajo, este último relacionado con la restricción migratoria, así como, la acumulación de recursos económicos y materiales sin que se amenace con un aumento en el monto de la pensión. Así mismo, destaca la afectación del PV en ámbitos familiares, especialmente en las relaciones de pareja y el ejercicio de la paternidad.

Esto parece producir sentimientos de frustración, incrementados por el aparente trato diferenciado hacia los hombres en los juzgados $y$ otras instituciones públicas, donde parece etiquetarse al varón como un ser violento e incapaz de la crianza de la prole y que, ante atrasos en el pago de la obligación alimentaria, ven perjudicada su integridad como seres humanos por la forma en como son tratados en espacios públicos, incluido su lugar de trabajo, situaciones que deben ser consideradas entre las personas servidoras de las instituciones que atienden estos casos, para mejorar la gestión, en apego al derecho que tienen todas las personas en ser tratadas con respeto $y$ de forma digna.

La influencia de las demandas de PA en el $\mathrm{PV}$ es multicausal, lo cual obedece a la integralidad de las personas y su intersubjetividad para el afrontamiento de las experiencias de vida, tanto para la parte actora, en su mayoría mujeres, como a la parte demandada, varones en mayor número, $y$ por supuesto a los jueces, seres humanos que deciden con base en dicha condición. 


\section{REFERENCIAS}

Aguilar, A. (23 de octubre, 2017). El suicidio es la tercera causa de muerte en adolescentes de Costa Rica. AMPrensa. com. Recuperado de https://amprensa. com/2017/10/suicidio-la-tercera-causamuerte-adolescentes-costa-rica/

Asamblea Legislativa. (23 de enero, 1997). Ley No 7654. Ley de Pensiones Alimentarias. Diario Oficial La Gaceta, (16). San José, Costa Rica.

Betancourth, S. y Cerón, J. (2017). Adolescentes creando su proyecto de vida profesional desde el modelo DPC. Revista Virtual Universidad Católica del Norte, 50(2141), 20-41. ISSN: 0124-5821.

Blanco, L., Martínez, J. y Villate, E. (2014). Fortalecimiento del vínculo afectivo de la tríada Padre-Hijo-Madre a través del curso de preparación para la maternidad y la paternidad "Un proyecto de vida": un estudio de caso. (Trabajo final de graduación Maestría en Enfermería con énfasis en Gerencia), Universidad Nacional de Colombia, Bogotá, Colombia.

Cascante, S. (8 de octubre, 2016). Las 7 causas de suicidio en Costa Rica, alerta Hospital Psiquiátrico. La Prensa Libre. Recuperado de http://www.laprensalibre. cr/Noticias/detalle/82056/las-7-causasde-suicidio-en-costa-rica,-alerta-hospital-psiquiatrico

Ceciliano, J., Jiménez, R., Quesada, O., Rodríguez, C. y Sandí, K. (2017). Endeudamiento de los consumidores en Costa Rica. Encuesta Actualidades 2017. Recuperado de https:/www.ucr.ac.cr/ medios/documentos/2017/estadistica-ucrencuesta-actualidades-2017-.pdf

Colín, R. y Monterrubio, E. (2010). La subjetividad como factor determinante en el sentido de una sentencia penal. Ciencia Ergo Sum, 17(2), 177-182. ISSN: 14050269 .

Davey, G. (2009). Using Bourdieu's concept of Habitus to explore narratives of transition. European Educational Research Journal, 8(2), 276-284. Recuperado de https://doi.org/10.2304/eerj.2009.8.2.276
Dávila, O., y Ghiardo, F. (2005). Trayectorias, transiciones y condiciones juveniles en Chile. Nueva Sociedad, (200), 114-126.

De Mézerville, G. (2005). Ejes de salud mental: los procesos de autoestima, dar y recibir afecto y adaptación al estrés. Ciudad de México, México: Trillas.

Dirección de Tecnología de Información del Poder Judicial. (2017). Estadísticas solicitudes de órdenes de apremio. San José, Costa Rica.

García, A., Hidalgo, M., López, M. y Román, R. (2018). Los micromachismos en los adolescentes. Su asociación con las relaciones de pareja y el modelo de maternidad y paternidad. Cultura de los Cuidados, (22), 144-153. doi:http://dx.doi. org/10.14198/cuid.2018.51.1

García, M. y Forero, C. (2014). Cambio organizacional y percepción de la justicia organizacional en una entidad de la ciudad de Bogotá-Colombia. Revista Diversitas, 10(2), 93-305. ISSN: 1794-9998.

Gil, E. (2009). Trayectorias y transiciones. ¿Qué rumbos? Reflexiones sobre la juventud del siglo XXI, 9(87), 15-30.

Gómez, V. y Royo, P. (2014). Nuevas subjetividades y proyecto de vida: jóvenes universitarios de la vil región del Maule, Chile. Revista de Estudios Sociales, (53), 90-101. Recuperado de https://doi. org/10.7440/res53.2015.07

González, J. (2017). Ciudadanía liberal, proyecto de vida $y$ autodeterminación: los derechos individuales como camino o como límite de la construcción de la identidad. Vniversitas, (135), 165-192. ISSN: 00419060.

Granada, C. (2011). Una revisión de la producción de conocimiento sobre transiciones $y$ trayectorias laborales juveniles. Virajes, (13), 309-334. Recuperado de http://vip.ucaldas.edu.co/virajes/downloads/Virajes13_13.pdf

Hernández, A. (2018). El derecho a los propios alimentos. Revista Judicial, Poder Judicial de Costa Rica, (122), 53-62. ISSN: 2215-237. 
Hernández, R. y Carranza, R. (2017). Felicidad, optimismo y autorrealización en estudiantes de un programa de educación superior para adultos. Interdisciplinaria, 34(2), 307-325. ISSN: 0325-8203.

Lizardo, O. (2004). The cognitive origins of Bourdier's Habitus. Journal of the Theory of Social Behaviour, 34(4), 375-401. Recuperado de https://doi. org/10.1111/j.1468-5914.2004.00255.x

Manuel, A.I., Sicilia, Á., Lirola, M. y Burgueño, R. (2016). Efectos de la satisfacción y frustración de las necesidades psicológicas básicas sobre las formas de pasión por el ejercicio. Psychology, Society \& Education, 8(3), 257-272. Recuperado de http://dx.doi.org/10.25115/psye.v8i3.188

Manzanos, C. (2004). Factores sociales y decisiones judiciales. Sociológica, (5), 127159. Recuperado de https://core.ac.uk/ download/pdf/61895085.pdf

Mora, M. y Oliveira, O. (2009). Los jóvenes en el inicio de la vida adulta: trayectorias, transiciones y subjetividades. Estudios sociológicos, 27(79), 267-289. ISSN: 0185-4186.

Nassar, R. (2015). La restricción migratoria como medida cautelar en la Ley de Pensiones Alimentarias. (Trabajo final de graduación para optar por el grado de Máster en Derecho Constitucional, Universidad Estatal a Distancia). San José, Costa Rica.

Organización Mundial de la Salud. (2018). Preguntas más frecuentes. Recuperado de http://www.who.int/: http://www.who. int/suggestions/faq/es/

Papalia, D. y Martorell, G. (2017). Desarrollo humano. (13 ${ }^{\mathrm{a}}$. ed.). Madrid: McGraw-Hill.

Pereira, T. (2012). Mediación docente de la orientación educativa y vocacional. San José: EUNED.

Ramírez, J. (2015). Orientación Vocacional Ocupacional: un análisis desde la teoría humanista existencial y la formación a nivel superior. Revista Veritatem, 1(1), 167-188.

Ramírez, J. (2016). Repercusiones del consumismo en el proyecto de vida: un análisis desde la educación ciudadana.
Revista Electrónica Educare, 20(2), 1-20. Recuperado de http://dx.doi. org/10.15359/ree.20-2.2

Rojas, P. (14/08/2013). Poder Judicial tramitó 138 mil casos por pensión alimentaria en los últimos cinco años. Recuperado de http://www.crhoy.com/archivo/poderjudicial-tramito-138-mil-casos-por-pension-alimentaria-en-los-ultimos-cincoanos/nacionales/

Ruiz, G. (09/02/2017). Proponen que las pensiones alimentarias oscilen entre $\$ 38.000$ y $\$ 720.000$ por niño. Recuperado de https://www.nacion.com/el-pais/politica/ proponen-que-las-pensiones-alimentarias-oscilen-entre-c-3

Schultz, P. y Schultz, S. (2010). Teorías de la personalidad. (9a . ed.). Madrid: Cengage Learning.

Sección de Estadística del Departamento de Planificación del Poder Judicial. (2013). Personas fallecidas en Costa Rica por suicidio durante el 2013. Anuario Policial 2013, 1-28. Recuperado de https://www. poder-judicial.go.cr/planificacion/images/documentos/estadisticas/policiales/Anuario_Policial_2013/Elementos/ PDFs/09_sumario_suicidios.pdf

Urzúa, A. y Caqueo-Urízar, A. (2012). Calidad de vida: Una revisión teórica del concepto. Revista Terapia Psicológica, 30(1), 61-71. Recuperado de http://dx.doi.org/10.4067/ S0718-48082012000100006

Vakil, R. (2018). Researching of dependence between the self-realization and academic achievement of the students from different professional occupations. Revista Dilemas Contemporáneos: Educación, Politica y Valores, 2(3), 1-28.

Vásquez, J. (7 de mayo, 2017). Promedio de pensión alimentaria es de menos de 43 mil por dia. Recuperado de https://www. crhoy.com/reportaje-especial/promediode-pension-alimentaria-es-de-menos-de$\%$ C2\%A23-mil-por-dia

Fecha de ingreso: 06/09/2018 Fecha de aprobación: 10/12/2018 